\title{
A política externa da Rússia: 0 Referendo da Criméia e os efeitos na região do Nagorno-Karabakh
}

Russian foreign policy: Crimea referendum and his effects to Nagorno-Karabakh

João Ricardo Guilherme Zimmer Xavier ${ }^{1}$

\section{RESUMO}

O objetivo do presente trabalho é apresentar as características da política externa russa para a região da Ucrânia e do Cáucaso e como essas políticas interferem no descongelamento do conflito do Nagorno-Karabakh. Foi analisado, através de uma coleta de dados bibliográficos e de notícias, que o referendo na Criméia e a conseqüente anexação têm a capacidade de agravar outros conflitos da região, mais especificamente o conflito do Nagorno-Karabakh.

Palavras Chave: Rússia; Criméia; Nagorno-Karabakh

\section{ABSTRACT}

The objective of this paper is to present the characteristics of Russian foreign policy for Ukraine and the Caucasus and how this policies affect the defrosting of Nagorno-Karabakh conflict. It was analyzed through a bibliographic and news data collection, the referendum of Crimea and the resulting annexation is able to exacerbate other conflicts in the region, specially the Nagorno-Karabakh conflict.

Keywords: Russia, Crimea, Nagorno-Karabakh

\section{Introdução}

O referendo de 2014, que promoveu a integração da Criméia, afetou não somente Rússia e Ucrânia, mas indiretamente todos os seus vizinhos da região, especialmente os países que possuem movimentos separatistas consideráveis, entre eles o território do Nagorno-Karabakh, o qual pertence ao Azerbaijão, porém é ocupado por forças

\footnotetext{
1 Mestrando em Ciência Política pelo Programa de Pós-Graduação em Ciência Política (PPGCP) da Universidade Federal do Paraná. Pesquisador do Núcleo de Relações Internacionais da UFPR (NEPRI), Curitiba, Brasil.
} 
armênias. A tensão na linha de cessar-fogo só vem crescendo e soluções definitivas devem ser discutidas. A opção militar não é descartada pelo Azerbaijão.

O interesse da Rússia no Cáucaso é um elemento importante para a análise desse transbordamento do conflito para essa região. Suas atitudes refletem diretamente nas políticas dos países próximos e em suas decisões políticas e estratégicas.

0 artigo será dividido em uma duas partes, mais as considerações finais: a primeira abordará a política externa russa e a anexação da Criméia; e a segunda será uma análise breve do conflito do Nagorno-Karabakh e as possibilidades de uma retomada ao conflito.

\section{A política externa russa e a anexação da Criméia}

Depois do colapso da União Soviética, o governo russo, mais especificamente o personalista Vladimir Putin, tenta restaurar a esfera de influência na região. De acordo com Starr e Cornell (2014), isso é feito das mais variadas formas: pressões políticas e diplomáticas, para a derrubada de regimes que venham a ser contra os interesses de Moscou; alimentação de conflitos congelados, como Criméia, Ossétia, Transnistria e Nagorno-Karabakh; pressões econômicas, especialmente na questão energética; apoio a extremistas de acordo com os interesses; além da propaganda e subversão, características de sua antecessora União Soviética, tão bem replicadas pelo governo de Putin.

Conforme analisado por Mankoff(2009), a demanda dos eurasianistas, grandes influenciadores da política russa, faz com que o Kremlin tome decisões de expansão do orçamento militar e de uma pressão maior na Ucrânia e nos países do Cáucaso, principalmente a Geórgia e a Armênia.

Mearsheimer (2014) analisa que o principal motivo da crise é a tentativa dos Estados Unidos e da União Europeia de retirar a Ucrânia da zona de influência da Rússia, e o alargamento da OTAN para a região.

“Washington pode não gostar da posição de Moscou, mas deve entender a lógica por trás. Isso é o básico da geopolítica: Grandes potências são sempre 
sensíveis a potenciais ameaças perto de seu território" (MEARSHEIMER,2014, tradução nossa) ${ }^{2}$

Com todos esses artifícios e o contexto turbulento na Ucrânia, junto a fortes afirmações de Putin, que diz corrigir um erro histórico ao retomar a Criméia, facilitou a incitação à população russa que vive na região, para que realizassem o plebiscito de Independência da Criméia e da base de Sevastopol, ponto estratégico da Rússia no Mar negro.

Com o plebiscito vencido facilmente pelos membros pró-Rússia, devido a boicotes de tártaros e Ucranianos (PETERS,2014), a Criméia e a cidade de Sevastopol foram rapidamente incorporadas pelo governo russo, além da constante ameaça no leste ucraniano, na região de Donetsk, também de maioria russa.

De acordo com Peters(2014), a legalidade de um referendo depende de quatro condições: o território deve estar pacificado anteriormente; sufrágio universal, igual, livre e secreto; liberdade de imprensa e neutralidade das autoridades; e o acompanhamento de observadores internacionais.. Nenhum destes quatro conjuntos de normas jurídicas internacionais foi respeitado na Criméia durante o referendo de 2014.

Com o referendo consolidado, há um precedente importante para os países com conflitos congelados ou territórios que buscam independência, como é o caso do Nagorno-Karabakh, e a atitude e os interesses da Rússia passam a ser determinantes para isso.

\section{O conflito do Nagorno-Karabakh}

A região do Nagorno-Karabakh fica no sul do Cáucaso, dentro do território da república do Azerbaijão. No século XVIII era um dos reinos azeris que tinham como objetivo ser uma oposição à influência do império Otomano, conforme analisado por Baguirov (2008), e o território é reconhecido internacionalmente sendo do Azerbaijão. Mmas, atualmente, a maioria absoluta da população é de armênios, mantendo uma república auto-proclamada com o nome de República do Nagorno-Karabakh, com nenhum país a reconhecendo internacionalmente.

\footnotetext{
2 No original:" Washington may not like Moscow's position, but it should understand the logic behind it. This is Geopolitics 101: great powers are always sensitive to potential threats near their home territory."
} 
As duas repúblicas envolvidas diretamente no conflito, a Armênia e o Azerbaijão, entre os anos de 1921 até o início da liberdade política na União Soviética, conhecida como Perestroika em 1987, foram controladas para que nenhum conflito surgisse. Em 1921, o então comissário de nacionalidades da república soviética russa, Joseph Stálin, confirma a posse das regiões do Nagorno-Karabakh e Nakhijivan para o Azerbaijão, como parte do tratado de amizade e irmandade entre a república soviética russa e a república da Turquia, para evitar uma Armênia forte que pudesse ter interesses territoriais na nascente república turca, que poderia gerar problemas na região. (CORNELL, 1999)

No inicio do ano de 1992, o vácuo de poder criado pela Dissolução da União Soviética terminou com o último fator que continha o conflito. Com a iminente retirada das ex-forças soviéticas, Karabakh passa a ser o cenário de uma crescente guerra de larga escala. 0 lado armênio, que havia se preparado para resolver o conflito por meios militares, não perdeu tempo para agir. No inicio de fevereiro, os vilarejos azeris de Malybeli, Karadagly e Agdabam foram conquistados e a sua população expulsa, levando pelo menos 99 civis mortos e 140 feridos. (CORNELL, 1999, apud YUSUNOV, p.3133)

Durante o conflito, os organismos internacionais, como a Organização das Nações Unidas (ONU), condenavam as ações da Armênia e afirmavam que o território pertencia ao Azerbaijão, com as resoluções 822, 853,874 e 884 do Conselho de Segurança.

“[...] Reafirmando a soberania e a integridade territorial da República do Azerbaijão e de todos outros estados na região. [...] Solicita ao Governo da Armênia usar sua influência para conseguir o cumprimento pelos armênios da região de Nagorno Karabakh, na República do Azerbaijão, com as resoluções 822 (1993), 853 (1993) e 874 (1993), e para garantir que as forças envolvidas não disponham dos meios para ampliar ainda mais sua campanha militar." (NAÇõES UNIDAS, 1993, p1-2, tradução nossa) ${ }^{4}$

\footnotetext{
3 "By early 1992, the power vacuum created by the dissolution of the Soviet Union led to the loss of the last factor containing the conflict. Thus with the imminent withdrawal of the formerly Soviet forces, Karabakh became the scene of what gradually increased to a full-scale war. The Armenian side, having prepared itself to solve the conflict through military means, did not loose any time to act. From early February onwards, the Azeri villages of Malybeili, Karadagly, and Agdaban were conquered an their population evicted, leading to at least 99 civilian deaths and 140 wounded."
}

$4 \quad$ No original:" Reaffirming the sovereignty and territorial integrity of the Azerbaijani Republic and of all other States in the region,[...] Calls upon the Government of Armenia to use its influence to achieve compliance by the Armenians of the Nagorny Karabakh region of the Azerbaijani Republic with resolutions 822 (1993), 853 Conjuntura Global, vol. 4 n.3, set./dez., 2015, p. 296-304. 
Com um acordo de cessar fogo firmado em 1994, manteve-se um status de conflito congelado, com muita tensão entre as duas partes na linha de contato, e sem um acordo definitivo. Para completar a dificuldade de solução do conflito, as potências pouco se esforçam para a resolução em definitivo, variando entre engajamentos temporários, quando a situação na linha do cessar fogo fica complicada, com mortes e discursos mais acalorados, e longos períodos de distanciamento. (CORNELL,2013)

\section{Possibilidades de retomada do conflito e soluções propostas.}

Devido a tensão na fronteira, somado ao fato de que o movimento separatista da Criméia rapidamente pode influenciar os armênios que ocupam a região do NagornoKarabakh a buscarem seu reconhecimento, faz com que a situação demande uma solução o quanto antes possível.

Conforme analisado por Cornell (2013), essas duas últimas décadas, o conflito foi considerado congelado, porém o status quo não é possível de se manter, pois a balança de poder mudou consideravelmente nos últimos anos: a emigração armênia decrescendo sua população e a economia pujante e rica em petróleo do Azerbaijão, que a partir de 2011 passou a ter um Produto Interno Bruto (PIB) cinco vezes maior que o da Armênia, e com um orçamento militar maior que o PIB do país vizinho. Juntando isso ao fato de que não existem forças de paz na região e que as ideias nacionalistas dos dois países estão sempre ao extremo, faz com que soluções por meios militares pareçam cada vez mais prováveis.

As soluções propostas pelas grandes potências, através do grupo de Minsk, composto por França, Estados Unidos e Rússia, incluem os princípios de Madrid, criados em 2007, e consistem em: retorno dos distritos adjacentes ao Nagorno-Karabakh para o Azerbaijão; garantias de segurança para os civis das duas nacionalidades; corredor conectando o território do Nagorno-Karabakh com a Armênia; retorno dos deslocados internos para os territórios ocupados; futura decisão que represente a vontade do povo da região para decidir entre a independência ou uma autonomia sem se desvincular do Azerbaijão; e que forças de paz internacionais garantam o período de transição. Porém

(1993) and 874 (1993), and to ensure that the forces involved are not provided with the means to extend their military campaign further" 
as duas partes não conseguem chegar ao acordo, e os representantes do grupo de Minsk também pouco fizeram para uma solução rápida. (KASIM,2012)

De acordo com Cornell (2013), a Rússia vem perdendo a credibilidade como mediadora, especialmente devido ao fato de ser uma vendedora de armas para os dois lados. Além disso, a Rússia possui uma base em Gyumri, na Armênia, em moldes parecidos com o antigo acordo com Sevastopol. Para completar a Rússia, através da renovação do acordo pela base de Gyumri, enviou diversos armamentos, substituindo a cláusula em que se comprometia a ajudar a Armênia em caso de ataque por qualquer não membro da Comunidade de Estados Independentes (uma clara referência a Turquia).

De acordo com Pashayeva e Göksel (2011) podemos enumerar alguns motivos pelos quais que "detalhes técnicos" dos principais acordos não são capazes de serem resolvidos: as mudanças no comportamento dos armênios, que consideravam os distritos adjacentes como uma zona de segurança e agora os consideram como zonas liberadas ou territórios historicamente armênios, ou seja, não querendo devolver aos azerbaijaneses; a falta de confiança histórica entre as duas partes e o receio de ceder mais do que o outro e sair perdendo; e a manipulação da Rússia para manter a sua esfera de influência, a qual indica um interesse na manutenção do status quo, enquanto não for a responsável direta pela missão de paz.

Com a recente vitória na questão da Criméia, a Rússia tende a não precisar se comprometer e fazer acordos com o ocidente sobre temas relativos a sua área de influência, tornando a situação ainda mais complexa, tanto para as partes beligerantes como para as outras partes interessadas. (SHAFFER,2014)

\begin{abstract}
Assim que a crise atingiu a Criméia, tanto a Armênia quanto o Azerbaijão endureceram imediatamente as suas posições sobre o conflito. Presidente armênio, Serzh Sargsyan ,chamou Putin e lhe deu uma medida parcial de apoio, embora mesmo isso tenha sido o suficiente para a Ucrânia para retirar seu embaixador de Yerevan. Sargsyan apoiou a primeira metade da manobra, o referendo da Criméia, mas não disse nada sobre direito de anexação da Rússia.(DE WAAL, 2014) ${ }^{5}$
\end{abstract}

$5 \quad$ As soon as the Crimea crisis struck, both Armenia and Azerbaijan immediately hardened their positions on the conflict. Armenian President Serzh Sargsyan called Putin and gave him a half measure of supportalthough even that was enough for Ukraine to recall its ambassador from Yerevan. Sargsyan supported the first half of the maneuver, the Crimean referendum, but said nothing about Russia's right of annexation. 
Enquanto isso, de acordo com De Waal (2014), o governo azerbaijanês apoia a Ucrânia e chegou a fazer um discurso mais acalorado, não só afirmando que o Karabakh é históricamente azerbaijanês, como também que uma considerável parte da Armênia também é.

Assim como a Ucrânia, o Azerbaijão faz parte do grupo de países parceiros da União Europeia, e entende que o apoio a soberania ucraniana é valido, porém deveriam adotar o mesmo padrão com a defesa da soberania do Azerbaijão na questão da região do Nagorno-Karabakh e dos sete distritos adjacentes. Durante o início do movimento Euromaidan ${ }^{6}$, o Azerbaijão ficou neutro, porém a ocupação da Criméia influenciou a opinião pública e os governantes do país a favor da Ucrânia. (VALIYEV, 2014)

Entretanto, de acordo com Valiyev (2014), isso não faz com que as relações entre Azerbaijão e Rússia sejam drasticamente abaladas, inclusive com aumento do comércio de armas e um considerável apoio em outras resoluções contra a Rússia, apenas se opondo a ocupação da Criméia sobre o principal argumento da política externa do Azerbaijão de integridade territorial, também utilizado para a resolução do conflito do Nagorno-Karabakh.

Os Estados Unidos após a anexação da Criméia ainda buscam soluções para o conflito do Nagorno-Karabakh o mais breve possível, porém tendem a falhar por ignorar aspectos importantes no conflito, em especial a importância da Rússia, por várias vezes culpando os presidentes da Armênia e do Azerbaijão por não prepararem sua população para a paz, ao invés de contribuir e elaborar um acordo eficiente em conjunto com os russos. (SHAFFER,2014)

Enquanto as partes envolvidas e os outros países interessados não chegam a um acordo, a situação fica cada vez pior na fronteira e os discursos cada vez mais ríspidos, tornando a opção militar algo considerável e de consequências incalculáveis.

\footnotetext{
6 Euromaidan foi o movimento de vários protestos na Praça da Independência, em Kiev, e depois em toda a Ucrânia com o objetivo de apoiar o acordo com a União Europeia, rejeitar o acordo aduaneiro com a Rússia e logo após a derrubada do presidente Viktor Yanukovich 


\section{Considerações Finais}

0 referendo e a consequente anexação da Criméia pela Rússia fez com que a região viva um período conturbado que afeta a todos os vizinhos, especialmente os que possuem disputas territoriais de alguma semelhança. Nesse contexto, somado a outras influências como tensões em linhas de contato, o conflito do Nagorno-Karabakh parece cada vez mais próximo de uma volta à fase armada, caso as organizações internacionais e especialmente as grandes potências não intervenham para uma solução pacífica.

Com interesses políticos, pois a Armênia é um aliado relevante na região, e econômicos, para freiar os avanços do Azerbaijão como alternativa de distribuição de petróleo e gás para o ocidente, a Rússia ganha com a manutenção do status quo, ao contrário da situação da Criméia, onde a anexação era a alternativa mais vantajosa para o país.

Ainda assim, para que uma solução para o conflito seja completa, é necessário: um engajamento real da Rússia e das outras potências interessadas; forças de paz para o retorno dos deslocados e para segurança dos azerbaijaneses e dos armênios no Nagorno-Karabakh; a liberação dos sete distritos adjacentes ocupados; e que os projetos econômicos do Azerbaijão proporcionem um desenvolvimento para a região, para as duas nações sejam beneficiadas. Mas, para isso, ainda resta um longo e desgastante processo, que pode resultar em um novo conflito se nada for feito a respeito.

\section{Bibliografia}

BAGUIROV, A Nagorno-Karabakh: basis and reality of Soviet-era legal and economic claims used to justify the Armenia-Azerbaijan war. Caucasian Review Of International Affairs, Frankfurt, vol. 2, n. 1, p.1-14, 2008. Disponível em: <http://www.cria-online.org/2_3html>. Acesso em: 11 jun. 2014.

CORNELL, Svante E. The Nagorno-Karabakh Conflict. Uppsala: Department Of East European studies, 1999.164p. Disponível em <http://www.silkroadstudies.org/new/inside/publications/1999_NK_Bookpdf >.Acesso em: 15ago. 2014.

. Russia and the unresolved conflicts in Eurasia. In: GÖKSEL, Diba Nigâr, SHIRIYEV, Zaur. The geopolitical scene of the Caucasus: A decade of perspectives. Istambul: Nisan, 2013.

DE WALL, Thomas, Crimea and Karabakh. In: Carnegie Moscow Center, 26.Mar 2014 Disponível em: http://carnegieru/eurasiaoutlook/?fa=55100

KASIM, Kamer. The Nagorno-Karabakh conflict: regional implications and the peace process. Caucasus International, Ankara, vol.2 n.1, p 93-110, spring 2012. 
MANKOFF, Jeffrey. Russian Foreign Policy: The Return of Great Power Politics. Maryland:Rowman \& Littlefield, 2009.

MEARSHEIMER, John J. Why the Ukraine Crisis Is the West's Fault: The Liberal Delusions That Provoked Putin. Disponivel em:< http://www.foreignaffairs.com/articles/141769/john-j-mearsheimer/why-the-ukrainecrisis-is-the-wests-fault> Acesso em 17 set 2014.

NAÇÕES UNIDAS.Conselho de Segurança das Nações Unidas. Resolução 884. Nova Iorque:1993.2 p.

PASHAYEVA, G.; GOKSEL, D.N.. The Interplay of the approaches of Turkey, Russia and the United States to the conflict over Nagorno-Karabakh. SAM. Baku Fev.2011 31p.

PETERS, Anne. Sense and Nonsense of Territorial Referendums in Ukraine, and Why the 16 March Referendum in Crimea Does Not Justify Crimea's Alteration of Territorial Status under International Law. Disponível em :<http://www.ejiltalk.org/sense-and-nonsenseof-territorial-referendums-in-ukraine-and-why-the-16-march-referendum-in-crimeadoes-not-justify-crimeas-alteration-of-territorial-status-under-international-law/> Acesso em 7 jan. 2016

SHAFFER, Brenda. Nagorno-Karabakh After Crimea: How Moscow Keeps the Conflict Alive -- And What to Do About It. In: Foreign affairs. 3. Mai 2014 Disponível em: https://www.foreignaffairs.com/articles/armenia/2014-05-03/nagorno-karabakhafter-crimea

STARR, S. Frederick; CORNELL, Svante E. Tactics and Instruments in Putin's Grand Strategy. In: STARR, S. Frederick; CORNELL, Svante E. Putin's Grand Strategy: The Eurasian Union and Its Discontents. Stockholm: Silk Road Studies Program, 2014.

VALIYEV, A. Azerbaijan's Balancing Act in the Ukraine Crisis. PONARS Eurasia Policy Memo No. 352. Set. 2014. Disponivel em: http://www.ponarseurasia.org/sites/default/files/policy-memospdf/Pepm352_Valiyev_Sept2014.pdf Acesso em: 4 jan 2016

YUSUNOV, Arif,"The Status of Nagorno- Karabakh: The Root of Conflict", in LIBARDIAN, G. YUSUNOV, Arif, New Approaches to Nagorno-Karabakh: A Window of Opportunity?, East-West Institute Policy Brief no. 3, 1998. 